Vol. 1, No. 1 (2020): 35-54

http://journalsttcipanas.ac.id/index.php/NPTRS/

p-ISSN 2722-9726, e-ISSN 2722-9718

Published by Sekolah Tinggi Teologi Cipanas (Cipanas Theological Seminary)

\title{
Model Pemuridan yang Relevan untuk Pelayanan Pendidikan Kristen
}

\author{
Oinike Laia \\ Universitas Kristen Indonesia \\ Email: oinikelaia@gmail.com
}

\begin{abstract}
The objective of Christian education is to build and mature the faith of students to become true disciples of Christ. But in its application the goal was not achieved even the educational orientation tended to shift only to fulfill the academic demand alone. So the purpose of this research is to study the teaching of Christian education and try to find methods that are relevant for Christian education services. The study uses descriptive qualitative methods and qualitative analysis of the concepts and application of Christian education, as well as conducting an objective assessment of the problems that occur from research findings. The next discussion will be to study the concept of discipleship and its relationship with Christian education. Through the results of the study it is hoped that it can produce biblical educational ideas or models, so that they can build an educational foundation and restore the function of Christian education, not only to produce academically qualified graduates but also to produce more faithful students. In the last discussion will propose a model or approach to discipleship that can be applied in the Christian community specifically in the educational environment both at the High School level and University or Colleges.
\end{abstract}

Keywords: Discipleship, Christian education, educational practitioners (leaders), disciples, transformation

\begin{abstract}
Abstrak
Tujuan pendidikan Kristen adalah membangun dan mendewasakan iman peserta didik menjadi murid Kristus yang sejati. Tetapi dalam penerapannya tujuan tersebut tidak tercapai bahkan cenderung orientasi pendidikan bergeser hanya untuk memenuhi tuntutuan akadamis semata. Maka tujuan dari penelitian ini adalah melakukan pengkajian terhadap pengajaran pendidikan Kristen dan berupaya untuk menemukan metode yang relevan bagi pelayanan pendidikan Kristen. Penelitian menggunakan metode deskriptif kualitatif dan analisis kualitatif terhadap konsep dan penerapan pendidikan Kristen, serta melakukan pengkajian secara objektif terhadap permasalahan yang terjadi dari temuan penelitian. Pembahasan selanjutnya akan melakukan pengkajian terhadap konsep pemuridan dan hubungannya dengan pendidikan Kristen. Melalui hasil kajian tersebut diharapkan dapat menghasilkan gagasan atau model pendidikan yang alkitabiah, sehingga dapat membangun fondasi pendidikan dan mengembalikan fungsi pendidikan Kristen, bukan hanya menghasilkan lulusan yang berkualitas secara akademis tetapi juga menghasilkan peserta didik (murid) yang lebih beriman. Dalam pembahasan terakhir akan mengusulkan model atau pendekatan pemuridan yang dapat diterapkan dalam komunitas Kristen secara khusus di lingkungan pendidikan baik di tingkat Sekolah Menengah Atas dan di Perguruan Tinggi.
\end{abstract}

Kata kunci: Pemuridan, pendidikan Kristen, pelaku pendidikan (pemimpin), murid-murid, transformasi

\section{Pendahuluan}

The New Perspective in Theology and Religious Studies, Vol. 1, No. 1, 2020 - 35 
Hasil penelitian dalam bidang pendidikan Kristen pada abad ke-21 menunjukkan banyak tantangan yang dihadapi untuk pengajaran Kristen. Salah satu hasil penelitian dari Tan Giok Lie dalam konteks Indonesia, dan mengemukakan ada dua tantangan yang dihadapi oleh pendidikan Kristen, pertama tantangan dari dalam adalah; (1) Serangan dari pandangan filosofis humanistik sekuler, (2) kegagalan para pendidik dalam mendidik orang murid dengan kebenaran mutlak berdasarkan Alkitab. Tantangan yang kedua adalah berasal dari masyarakat yang semakin sekuler, baik dari sistem nilai dan kehidupannya." " Di era globalisasi pengaruh filsafat humanistik telah menyebar dan berdampak di sekolah-sekolah Kristen dan perguruan tinggi Kristen. Bahkan hampir seluruh praksis pendidikan di sekolah Kristen dibangun di atas filosofi pendidikan sekuler, yang membedakan di sekolah Kristen ditambahkan dengan kebaktian sekolah di tengah minggu, terdapat pelajaran Agama Kristen, retret tahunan dan yang lainnya. Tetapi pada umumnya lembaga pendidikan Kristen lebih menekankan prestasi akademis semata. ${ }^{2}$ Gambaran secara faktual dikemukakan melalui "Seminar Pendidikan Kristen" pada 12 Desember 2011 di Universitas Kristen Maranatha, Bandung. Hasil ground research menunjukkan bahwa ciri khas pendekatan dan terapan pendidikan Kristen sudah tidak ditemukan lagi atau ditinggalkan. Bahkan banyak sekolah Krsiten di beberapa daerah seperti Jakarta, Bandung, Manado, Jawa Tengah yang telah ditutup dan mengganti dengan nama sekolah umum. ${ }^{3}$ Penelitian dalam skala internasional yakni dilakukan di Amerika Utara dan hasil temuan disampaikan pada Institute for Excellence of Overseas Council, Singapura tahun 2009. Penelitian yang dilakukan adalah menyelidiki kehidupan kerohanian dari lulusan Sekolah Teologi, dan dari hasil penelitian semua jawaban para alumi sama sekali tidak menyinggung masalah kerohanian. Jawaban para pendidik juga menunjukkan hasil yang sama di mana yang ditekankan dalam pengajaran adalah kualitas akademis dan menyinggung pentingnya kehidupan spiritualitas. ${ }^{4}$

Memperhatikan kegagalan dari banyak Sekolah Kristen memberikan indikasi adanya kelemahan pelaksanaan pelayanan pendidikan Kristen di lembaga pendidikan.

\footnotetext{
${ }^{1}$ Tan Giok Lie, "Tantangan Pendidikan dan Pengajaran Kristen Masa Kini di Ranah Formal", dalam STULOS Jurnal Teologi, STT Bandung 2013, 6-13. Diposting oleh Redaksi e-Reformed: http://reformed.sabda.org. Diakses 10 Desember 2019.

${ }^{2}$ Ibid, 6-13.

${ }^{3}$ Ibid, 6-13..

4 Purnawan Tenibemas, "Spiritualitas di Sekolah Tinggi", dalam Jurnal Teologi Pengarah, Bandung: STT Tiranus, Juli 2010), 3-5.
}

36 - The New Perspective in Theology and Religious Studies, Vol. 1, No. 1, 2020 
Seperti dikemukakan oleh Harold Klasses, ia menjelaskan bahwa kegagalan dari banyak sekolah Krsiten disebabkan karena fondasi sekolah yang lemah dan terjebak dalam dualistik. Dalam pengalamatan di Sekolah Kristen Amerika fondasi sekolah Kristen cenderung bersifat pragmatis dan tidak integral dengan visi hidup Kristen yang sesungguhnya. ${ }^{5}$ Persoalan yang sama juga dihadapi oleh Sekolah Umum, seperti dikemukakan oleh A. Sudarja, bahwa permasalahan yang muncul dalam pendidikan di era globalisasi adalah "paradigma modern yang berpusat pada rasio, dan subjek pendidikan yang berpusat pada individu, dan mengabaikan tujuan pendidikan untuk kemanusiaan. Dampaknya adalah pembelajaran tentang kehidupan spiritual dianggap tidak relevan."

Berdasarkan permasalahan yang dikemukakan di atas di mana peran pendidikan Kristen nampaknya mengalami kegagalan bersama dengan keberadaan sekolah-sekolah Kristen yang mengalami pergeseran orientasi, sehingga kehidupan spiritual dianggap tidak relevan. Akibatnya fungsi pendidikan, secara khusus peran pendidikan Kristen untuk membangun kehidupan murid menjadi lebih baik, lebih beriman tidak tercapai. Oleh sebab itu dalam tulisan ini akan melakukan pengkajian terhadap konsep pendidikan Kristen dan penerapannya, serta mengusulkan model pemuridan sebagai solusi dalam pelaksanaan pelayanan pendidikan Kristen di lingkungan Sekolah.

\section{Pembahasan}

Pemaparan sebelumnya telah mengemukakan permasalahan yang dihadapi dalam lingkungan Sekolah Kristen dan kelemahannya peran pendidikan Kristen untuk mencapai tujuannya, membangun manusia yang memiliki kehidupan spiritual. Maka dalam bagian ini akan membahas dua topik utama, yakni, pertama, deksripsi dan kajian terhadap konsep pendidikan Kristen dan penerapannya. Kedua, menguraikan deskripsi dan kajian terhadap konsep pemuridan Kristen dan relevansinya terhadap tugas pendidikan Kristen.

\section{Pendidikan Kristen}

5 Harold Klassen, "Model Ketiga Sekolah Kristen Modern", dalam Transforming Teachers, Okober 2008: https://www.transformingteachers.org/en/articles/transformational-education. Diakses 10 Desember 2009.

6 A. Sudiarja, Pendidikan dalam Tantangan Zaman (Yogyakarta: Kanisius, 2014), 70.

The New Perspective in Theology and Religious Studies, Vol. 1, No. 1, 2020 - 37 
Pendidikan Kristen merupakan kebutuhan umat manusia dan memberi pengaruh penting terhadap praktik pendidikan masa kini. Tetapi karena beberapa faktor peranan tersebut mengalami kegagalan. Maka untuk menjawab permasalahan yang dihadapi oleh pendidikan Krsiten dalam bagian ini akan memaparkan dua topik; pertama mengenai pengertian, hakikat dan tujuan pendidikan Kristen, kedua mengenai karakteristik dan model pendidikan Kristen yang berdampak terhadap pendidikan masa kini.

Pengertian dan Hakikat, serta Tujuan dari Pendidikan Kristen

Pada umumnya semua pelaku pendidikan Kristen beranggapan bahwa pendidikan Kristen berperan penting dalam kehidupan manusia. Parker J. Palmer, mengemukakan bahwa "pendidikan Kristen adalah sebagai pencarian akan Tuhan atau perjalanan spiritual yang melibatkan seluruh aspek kehidupan manusia, dan mengikat seluruh pengetahuan yang diketahui, serta menciptakan ikatan antara diri sendiri, orang lain, dan seluruh dunia."7 Palmer menunjukkan bahwa pendidikan Kristen bertitik tolak dari perjalanan spiritual berjumpa dengan Tuhan, dan akan berpengaruh terhadap seluruh aspek kehidupan manusia. Pandangan lainnya dari John H. Westerhoff, ia mengemukakan bahwa yang diperlukan dalam pendidikan Kristen adalah pertobatan dan pemeliharaan. Jadi definisi pendidikan Kristen adalah "semua upaya gereja yang sengaja, sistematis dan berkelanjutan yang memungkinkan individu dan komunitas iman menjadi lebih Kristen, baik dalam kehidupan pribadi dan kehidupan bersama."8 Dalam pengertian ini menunjukkan bahwa pendidikan Kristen merupakan keharusan, karena bertujuan untuk membuat kehidupan manusia menjadi lebih baik dan lebih beriman.

Thomas H. Groome juga mengemukakan peranan penting dari pendidikan Kristen untuk kehidupan manusia. Di mana hakikat pendidikan Kristen adalah "kegiatan politis bersama para peziarah dalam waktu yang secara sengaja mereka bersama-sama memberi perhatian pada kegiatan Allah di masa kini, dan cerita komunitas iman Kristen,

${ }^{7}$ Parker J. Palmer, To Know As We Are Known: Educational As A Spiritual Journey (San Fransisco: Harper \& Row, 1993), 8-13.

${ }^{8}$ John H. Westerhoff III, Will Our Children Have Faith? (New York: The Seabury Press, 1976), 105.

38 - The New Perspective in Theology and Religious Studies, Vol. 1, No. 1, 2020 
serta visi Kerajaan Allah, serta benih-benih yang hadir di antara kita."9 Sedangkan tujuan pendidikan Kristen adalah "untuk mendorong orang ke arah iman Kristen yang dewasa”. Maka aspek-aspek penting dalam kegiatan pendidikan Kristen adalah: (1) harus menyentuh batiniah dan membimbing seseorang ke arah hubungan yang hidup dengan Allah di dalam Yesus Krsitus, (2) bersifat kognitif, yakni, sebagai kegiatan percaya, (3) bersifat afektif, yakni kegiatan mempercayakan, (4) Iman Kristen berhubungan dengan tingkah laku, yakni kegiatan melakukan, dan (5) merupakan proses perkembangan yang berlangsung seumur hidup dan meliputi kehidupan manusia seutuhnya. ${ }^{10}$ Pandangan yang sama juga dikemukakan oleh Richard J. Edlin, mengenai tujuan dari pendidikan Kristen. Ia mengemukakan dua tujuan pendidikan Kristen, yakni: (1) Pendidikan dirancang untuk menyampaikan dan memperkaya budaya, serta membantu kelancaran peran peserta didik dalam upaya memuliakan Kristus sebagai Tuhan atas semua ciptaan, (2) membantu para siswa belajar tentang dunia dan peran mereka di dunia sebagai Anak Allah. Maka pendidikan Kristen harus dilihat dalam terang alkitabiah. ${ }^{11}$

Mempelajari konsep pendidikan Kristen yang telah dipaparkan di atas maka semestinya pendidikan Kristen merupakan kebutuhan yang sangat penting dalam kehidupan manusia. Karena tugas pendidikan Kristen adalah membangun dan memperlengkapi peserta didik agar memahami identitasnya, menjadi manusia yang beriman di tengah dunia, serta menjalankan perannya untuk membawa kasih dan memberikan pengaruh kepada dunia. Untuk mendapatkan gambaran secara mendalam maka dalam pembahasan selanjutnya akan membahas mengenai karakteristik dan tujuan pendidikan Kristen.

\section{Karakteristik dan Penerapan Pendidikan Kristen}

Sesuai dengan pengertian dan hakikatnya pendidikan Kristen memiliki dua karakteristik, yaitu: (1) pendidikan Kristen di sekolah yang memiliki perspektif Kristen, melibatkan dan menantang peserta didik untuk memuliakan Kristus sebagai Tuhan atas

9 Thomas H. Groome, Christian Religious Education: Sharing Our Story and Vision. (San Fransisco: Harper \& Row, 1980), 15-16. Terj. Daniel Stefanus, Pendidikan Agama Kristen: Berbagi Cerita dan Visi Kita (Jakarta: BPK Gunung Mulia, 2010).

${ }^{10}$ Ibid, 107-103.

11 Richard J. Edlin. The Cause of the Christian Education, terj. Hakikat Pendidikan Kristen (Jakarta: BPK Gunung Mulia, 2014), 26-28.

The New Perspective in Theology and Religious Studies, Vol. 1, No. 1, 2020 - 39 
semua ciptaan. (2) Pendidikan Kristen juga harus melihat dunia sekitarnya untuk melakukan tugas-tugas sebagai anak-anak Allah berdasarkan panggilan Yesus Kristus. ${ }^{12}$ Penjelasan ini menunjukkan bahwa pendidikan Kristen berhubungan erat dengan panggilan pemuridan Kristus kepada murid-murid-Nya untuk menjadikan bangsabangsa sebagai murid Kristus. Maka semestinya ciri khas pelayanan pendidikan Kristen adalah membantu murid memahami dan mengalami penebusan Kristus serta membimbing mereka melakukan panggilan Yesus untuk meneruskan tugas pemuridan.

Menurut D.L Graham ciri pendidikan Kristen adalah membawa kasih Kristus di dalam proses pendidikan sekolah. Ciri pendidikan tersebut telah diterapkan di Alpha Christian School, yakni menerapkan pendidikan yang menebus. Dalam menerapkan ciri pendidikan yang menebus, seorang guru tidak mengajar untuk mengontrol murid, tetapi menuntun para murid dalam kasih dan anugerah-Nya, serta memberikan kesempatan agar mereka berkreasi. Maka yang diperhatikan adalah bagaimana murid-murid merefleksikan siapa Allah, apa yang dikerjakan Allah bagi umat manusia. Kemudian guru membantu murid-murid untuk memikirkan bagaimana cara menjaga alam dengan benar dan mengasihi sesama sesuai kasih Allah yang telah dipahami dan dialami oleh murid-murid. ${ }^{13}$ Jadi dalam model pendidikan yang menebus, murid-murid diarahkan untuk memiliki kesadaran untuk memuliakan Tuhan dengan keseluruhan hidup mereka.

Berdasarkan karakteristik pendidikan Kristen menunjukkan bahwa tugas utama pelayanan pendidikan Kristen adalah menjadikan murid. Karekateristik ini sesuai dengan arti dasar dari kata murid yang berasal dari bahasa Yunani, yakni didasko, artinya perbuatan mengajar sedemikian rupa, sehingga orang yang diajar dapat mengerti dan melakukan apa yang disampaikan pengajar. ${ }^{14}$ Dalam pengertian ini pemuridan merupakan ciri penting dalam pendidikan Kristen, yakni mengajar peserta didik melalui pengajaran praktis untuk menjadi murid Kristus yang disertai dengan keteladanan. Tugas penting dari pendidik adalah mencari model pendidikan bagi pembinaan iman murid agar pengajaran yang disampaikan dapat dipahami dan diterapkan dalam kesakisan (keteladan).

\footnotetext{
${ }^{12}$ Ibid, 56-57.

${ }^{13}$ Donovan L. Graham, Teaching Redemptively: Bringing Grace and Truth into Your Classroom (Colorado Sprin, CO: Purposeful Design Publications, 2003/2009), 78.

14 Asmat Purba, "Pemuridan sebagai Tugas Dosen Pendidikan Agama Kristen di Perguruan Tinggi”, dalam Jurnal Ilmiah Berkala, TEDC Vol, 8 No. 1 (Januari 2014), h.68-73.
}

40 - The New Perspective in Theology and Religious Studies, Vol. 1, No. 1, 2020 


\section{Pemuridan}

Pembahasan sebelumnya mengemukakan bahwa ciri pendidikan Kristen adalah pemuridan. Agar mendapatkan pemahaman yang mendalam maka dalam bagian ini akan memaparkan dua topik, yakni: (1) pengertian pemuridan, (2) penerapan pemuridan dalam pelayanan pendidikan Kristen.

Pengertian Murid dan Pemuridan

Pengertian pemuridan didasarkan pada Amanat Agung Yesus dalam Matius 28:18-20 yang meminta para pengikut-Nya untuk menyebarkan berita keselamatan kepada seluruh dunia. Bill Hull menjelaskan bahwa tugas yang dilakukan untuk melakukan pertintah tersebut dilakukan dengan kata kerja "pergilah, baptislah, dan ajarlah" dan tindakan utama dalam perintah Yesus adalah "jadikanlah segala suku bangsa menjadi murid-Ku" atau "membuat murid." Jadi tugas utama dalam pemuridan adalah membuat murid. ${ }^{15}$ Kemudian Hull menjelaskan stilah murid (disciple) berasal dari kata mathetes (Yunani), artinya seorang yang belajar dengan mengikuti gurunya, terjadi proses intelektual yang secara langsung memengaruhi gaya hidup seseorang. Secara spesifik Bill Hull mengemukakan lima karakteristik murid, yakni: (1) Murid harus tunduk pada pemimpin yaitu Kristus, (2) Murid mempelajari firman Yesus, (3) Murid mempelajari bagaimana Yesus melayani, (4) Murid mencontoh hidup dan karakter Yesus, (5) Murid harus mencari dan mengajar murid-murid lain untuk mengikut Yesus. Kemudian Hull menekankan bahwa pemuridan yang dilakukan oleh Yesus adalah mengarah pada transformasi kehidupan murid. ${ }^{16}$

Edmund Chan menjelaskan istilah murid berasal dari kata mathetes (Yunani), digunakan dalam proses belajar seseorang yang mencari pengetahuan dalam bidang tertentu. Istilah murid inilah yang digunakan dalam konteks pemuridan pada zaman Yesus. ${ }^{17}$ Kemudian pemuridan didefinisikan dalam empat aspek, yakni: (1) Pemuridan membawa orang ke dalam hubungan yang dipulihkan dengan Allah, (2) Pemuridan membina murid menuju kedewasaan di dalam Kristus, (3) Pemuridan dilakukan melalui rencana pertumbuhan yang intensional, (4) Pemuridan memberikan pengaruh agar

\footnotetext{
${ }^{15}$ Bill Hull, Jesus Christ, Disciplemaker, terj. Yesus Kristus, Sang Pembuat Murid (Grand Rapids: Baker Publishing Group, 2004 / Surabaya: Literatur Perkantas Jawa Timur, 2015), 23.

${ }^{16}$ Ibid, 24.

${ }^{17}$ Edmund Chan, A Certain Kind (Yang Tertentu): Pemuridan Intensional yang Mengubah Definisi Sukses dalam Pelayanan (Singapore: Covenant Evangelical Free Church, 2014), 46.
}

The New Perspective in Theology and Religious Studies, Vol. 1, No. 1, 2020 - 41 
murid-murid mampu melipatgandakan proses pemuridan kepada orang lain. ${ }^{18}$ Kemudian George Barna juga mendefinisikan istilah murid, yakni, pengikut Yesus yang setia, berpengetahuan, dan seorang pelaku firman. Sedangkan tugas pemuridan melibatkan keduanya, pemimpin memperlengkapi murid-murid dan respon murid untuk mengikuti pengajaran dan teladan dari pemimpin. ${ }^{19}$

Berdasarkan penjelasan di atas menunjukkan bahwa seluruh tugas pemuridan merupakan tugas pokok dari pendidikan Kristen, yakni membantu murid agar mampu memperjuangkan kasih, keadilan, kebenaran dalam keluarga, masyarakat, dan seluruh aspek kehidupan.

Penerapan Pemuridan dalam Pelayanan Pendidikan Kristen

Dietrich Bonhoeffer (teolog Lutheran Jerman) mengatakan bahwa pemuridan dapat diterapkan dalam lingkungan pendidikan. Di mana sentral pemuridan adalah menjawab pertanyaan tentang apa yang seharusnya terjadi dalam kehidupan orang Kristen dan kehidupan komunitas Kristen. Tugas normatif dalam pemuridan adalah membantu murid untuk memahami apa artinya mengikuti Yesus. Jawaban dari pertanyaan ini adalah empat gerakan pemuridan: (1) Landasan pemuridan adalah wahyu, perkataan Tuhan kepada dunia, wahyu adalah logos, dan sebagai sumber pengetahuan yang unggul. (2) Realitas pemuridan adalah hakikat gereja (Kristus dan komunitas). (3) Tindakan pemuridan adalah christopraxis, artinya teologi komunitas Kristen harus dimulai dari Kristus dan pelayanan ditemukan dalam Roh Allah melalui Yesus Kristus. (4) Pemuridan kristen merupakan model yang layak diterapkan untuk orang percaya yang sudah dewasa. Dengan demikian pemuridan dapat diterapkan dalam komunitas Kristen apapun, termasuk di lingkungan sekolah sebagai komunitas, di mana sumber utama dari pendidikan Kristen adalah pemuridan. ${ }^{20}$

Pada pertengahan abad ke-20, model pemuridan juga telah diterapkan dalam pendidikan Kristen sebagai solusi dari kegagalan Sekolah-sekolah Kristen di Amerika yang memuncak pada awal abad ke-20. Klassen menjelaskan salah satu perubahan yang dilakukan adalah mengembangkan gerakan sekolah Kristen modern dengan filosofi

\footnotetext{
${ }^{18}$ Ibid, 58-59.

${ }^{19}$ George Barna, Menumbuhkan Murid-Murid Sejati (Jakarta: Metanoia, 2010), 27.

${ }^{20}$ Brant Himes, "Dietrich Bonhoeffer As Theological Praxis: A Resource for Educational Ministry", dalam Christian Education Journal, Series 3. Vol. 8, No. 2 (Fuller Theologial Seminary, 2011), h. 263.
} 
pendidikan Kristen yang berbeda. Yakni menerapkan model pendidikan Kristen berbasis pemuridan dan pengajaran Kristen lebih terintegrasi dalam kesaksian hidup. Perubahan yang terjadi adalah selain mempertahankan misi dalam pendidikan Kristen, fokus pendidikan Kristen menekankan pemuridan, yakni, memperlengkapi peserta didik (murid) menjadi dewasa dan menjadi murid Kristus. Dampak positifnya adalah terjadi perkembangan Sekolah Kristen di Amerika Utara. ${ }^{21}$

Berdasarkan penjelasan di atas menunjukkan bahwa model pemuridan sangat berpotensi memberikan perubahan apabila diterapkan dengan serius dalam pelayanan pendidikan Kristen. Bahkan sudah seharusnya sekolah-sekolah Kristen masa kini menjalin relasi dengan gereja atau sebaliknya gereja harus berelasi dengan sekolah Kristen, dan fokus diskusi adalah bagaimana meyakinkan murid dan pelaku pendidikan agar memahami pentingnya model pemuridan dalam pendidikan Kristen. Sehingga pengajaran pendidikan Kristen bukan hanya sebagai talenta yang dibagikan kepada dunia atau sekedar transfer ilmu dari pendidik kepada peserta didik, melainkan melatih murid-murid dapat berlipatgandaadalah perubahan hidup peserta didik menjadi murid Kristus yang sejati. Dalam pembahasan selanjutnya akan memaparkan model pemuridan yang dapat digunakan dan diterapkan dalam lembaga pendidikan Kristen.

\section{Model Pemuridan yang Relevan untuk Pendidikan Kristen}

Bagian ini akan mengemukakan model pemuridan yang dapat diterapkan untuk mencapai tugas pendidikan Kristen, yakni: model pemuridan relasional, model pemurdan naratif, dan model kepemimpinan berpusat pada murid (disciple).

\section{Model Pemuridan Relasional}

Model pemuridan relasional diperkenalkan oleh Chris Shirley, ia menggunakan metode pemuridan yang dilakukan oleh Yesus, yakni, mempersiapkan murid-muridNya untuk menjangkau dunia. ${ }^{22}$ Salah satu teks rujukan dari Yohanes 15:1-16, yang menunjukkan bahwa Yesus melakukan pemuridan melalui hubungan (relasional), yang

${ }^{21}$ Harold Klassen, "Model Ketiga Sekolah Kristen Modern."

${ }^{22}$ Model pemuridan relasional juga merupakan salah satu strategi pemuridan yang diterapkan oleh Greg Ogden, yakni: (1) investasi relasi, (2) proses multiplikasi, (3) proses transforamasi. Strategi pertama adalah memuridkan melalui investasi relasi, artinya pemuridan merupakan perjalanan bersama dengan beberapa orang dalam sebuah relasi yang disengaja dari waktu ke waktu. Greg Ogden, Transforming Discipleship, terj. Pemuridan yang Mengubahkan (Surabaya: Literatur Perkantas Jawa Timur, 2014), 17.

The New Perspective in Theology and Religious Studies, Vol. 1, No. 1, 2020 - 43 
digambarkan dalam tiga hal, yakni: (1) tinggal di dalam Kristus, (2) bersekutu dengan murid-murid lain, (3) melayani kebutuhan orang lain di dunia dan di gereja. ${ }^{23}$ Ketiga titik hubungan tersebut merupakan standar untuk menentukan murid yang otentik dan hidup di dalam Kristus, serta bekerja untuk Kerajaan Allah. Implikasinya adalah pemuridan merupakan proses relasional yang melibatkan hubungan secara langsung dan ketaatan total kepada Tuhan, berkomitmen untuk bertemu dalam Kristus, melayani orang-orang yang belum mendengar Injil dan belum hidup dalam komunitas Kristen. ${ }^{24}$

Model pemuridan relasional dalam pelayanan Yesus ditunjukkan dalam Yohanes 15, tentang ajakan Yesus kepada murid-murid "tinggallah di dalam Aku". Arti "tinggal di dalam Kristus" adalah hidup yang tinggal di lokasi tertentu, dilakukan dengan ketekunan dan konsistensi yang berkelanjutan, dalam keintiman yang harmonis, dan terjadi secara timbal balik. ${ }^{25}$ Dengan demikian Yesus menggambarkan hubungan yang dibangunnya terhadap murid-murid sebagai cerminan dari hubungan antara Yesus dan Bapa. Maka panggilan untuk "tinggal di dalam Kristus" bermakna kualitas hubungan dalam pemuridan secara berkelanjutan, sebagai bukti bahwa murid telah mempunyai hubungan dengan Kristus. $^{26}$ Kemudina dalam Yohanes 15:12,17 menunjukkan relasional murid dengan Yesus dibuktikan dalam tindakan "saling mengasihi”, seperti yang terjadi dalam hubungan Yesus dengan murid-murid. Yesus mengajarkan tindakan mengasihi kepada murid-murid melalui perbuatan dalam kerendahan hati karena Ia menginginkan murid-murid mengekspresikan kasih di antara mereka, maka kasih merupakan daya tarik bagi masyarakat. ${ }^{27}$

Apakah model pemuridan relasional dalam pelayanan pendidikan Kristen? Apabila ditinjau dari penjelasan yang dikemukakan oleh Sherly, menunjukkan bahwa model pemuridan relasional sangat relevan untuk diterapkan dalam pelayanan pendidikan Kristen. Dengan model pemuridan maka kegiatan pendidikan digunakan sebagai sarana untuk membawa murid-murid mengalami perjumpaan dengan Kristus, tinggal di dalam Kristus dan menjadi murid Kristus. Hal ini juga sesuai dengan tujuan utama ataui fungsi dari pendidikan Kristen, yakni, mengajarkan para murid agar

${ }^{23}$ Chris Shirley, "Overcoming Digital Distance: The Challnge of Developing Relational Disciples in the Internet Age", dalam Christian Education Journal (Dallas Baptist University, 2017), Seri 3, Vol. 14, No. 2, 376.

${ }^{24}$ Ibid, 377.

${ }^{25}$ Ibid, 377.

${ }^{26}$ Shirley, 378

${ }^{27}$ Ibid, 378. 
menjadi murid Kristus dalam pikiran (pengetahuan/knowledge) dan dalam praksis (kesaksian/keteladanan) kehidupan sehari-hari.

\section{Pendekatan Pemuridan Naratif}

Pendekatan pemuridan naratif diperkenalkan oleh Natan C. Byrd sebagai model pemuridan untuk membantu orang percaya dewasa dapat mengidentifikasikan perjalanan imannya dan membangun landasan iman berdasarkan pembelajaran yang transformatif. Model pemuridan menggunakan teknik penelitian dan analisis narasi kualitatif terhadap pengalaman pahit dari seseorang, kemudian membimbingnya untuk menganalisa dan menafsirkan ceritanya sendiri dalam terang Firman Tuhan. Teori pemuridan naratif dikembangkan dari temuannya dalam penelitian terhadap pengalaman iman yang dialami oleh lulusan perguruan tinggi, dan telah menjadi pemimpin mahasiswa di salah satu organisasi Kristen berbasis universitas. Ketika melakukan penelitian, ia mendengar para mahasiswa (peserta) menceritakan perjalanan iman mereka, kemudian ia membimbing peserta agar langsung menghubungkan ceritanya tersebut dengan pengalaman yang berbeda, dan mengenali tema dari alur perjalanan hidup mereka. ${ }^{28}$ Dalam proses menceritakan kisah inilah maka para peserta dapat memberikan konteks di mana secara kritis mereka merefleksikan peristiwa dalam hidupnya yang sebelumnya terputus dan menjadi lebih mendalam. Cara yang dilakukan adalah dengan wawancara naratif, dan menyalin hasil wawancara dari 14 peserta partisipan penelitian. Selanjutnya melakukan analisis metode pemuridan dengan orangorang percaya yang dewasa yang telah diwawancara dan terlibat dalam pelayanan, baik di gereja maupun di perguruan tinggi. Dalam wawancara naratif tersebut Byrd menemukan bahwa pemuridan Kristen adalah proses membantu seseorang menjadi lebih seperti Yesus. Maka dalam proses pemuridan harus melibatkan unsur pendidikan, pembinaan rohani, dan konseling Kristen, serta keterampilan pembinaan. Proses ini dianggap relatif sederhana, dapat dilakukan dalam beberapa menit atau secara intensif, dan memberikan tempat pada pertemuan yang lebih banyak untuk bersama-sama. ${ }^{29}$

\footnotetext{
${ }^{28}$ Nathan C. Byrd, III, "Narrative Discipleship: Guiding Emerging Adults "Connect the Dots" Of Life and Faith", dalam Christian Education Journal, Series 3, Vol. 8, No.2 (La Mirada: Biola University, 2011), 246.

${ }^{29}$ Ibid, 246-247.
}

The New Perspective in Theology and Religious Studies, Vol. 1, No. 1, 2020 - 45 
Melalui hasil penelitiannya, Bryrd menemukan tiga prinsip penting dalam pemuridan naratif, yakni: (1) Teori identitas naratif (narrative identity theory), biasanya digunakan dalam tradisi Injili, di mana pengikutnya sering diajarkan membagikan kisah pengalaman iman mereka yang mewarnai perjalanan hidup dengan ekspresi keagamaan dan metafora teologis. Dalam teori identitas naratif orang Kristen belajar dengan melihat pengalaman masa lalu dalam terang keyakinan iman pada saat ini. Dengan demikian identitas manusia masa kini dapat dipahami melalui kisah yang dapat diingat dan cerita tentang diri sendiri. (2) Belajar di masa kedewasaan baru (learning in emerging Adulthood). Dalam pemuridan naratif diperlukan model pendampingan untuk orang dewasa baru yang terlibat dalam pelayanan di kampus, pelayanan kaum muda, atau orang dewasa lainnya dengan menggunakan pertanyaan yang membantu mereka dapat merefleksikan kehidupan dan imannya menjadi iman yang dewasa dan bijaksana. (3) Pembelajaran transformatif. Pada umumnya pertumbuhan dan perkembangan dalam pendidikan Kristen, pengembangan iman dan spiritual, serta pemuridan sering dilihat dari perspektif pertobatan atau perubahan kehidupan agama yang dramatis. Tetapi dalam teori pemuridan naratif yang diterapkan oleh Byrd, pemurid harus memiliki dampak besar dalam pendidikan orang dewasa dengan pembelajaran transformatif. ${ }^{30}$

Sebagai contoh untuk model pembelajaran transformatif dilakukan dengan mempelajari pengalaman seorang perempuan yang merupakan partisipan penelitiannya, dilakukan setelah ia kembali ke perguruan tinggi sebagai orang yang telah mengalami perubahan hidup menjadi dewasa dalam iman. Selanjutnya model pembelajaran transformatif tidak hanya dilakukan di ruang kelas, tetapi juga dapat digunakan dalam konseling psikologis serta pembelajaran transformatif dalam kedokteran. Menurut Byrd pembelajaran transformatif dapat membebaskan peserta didik dari ikatan, pengalaman, perspektif, dan konsep diri yang terbatas pada kehidupan masa lalu. Dalam proses ini pemurid (pendidik) dapat membantu murid untuk mengembalikan kehidupan mereka, dan peran pendidik adalah membantu murid untuk melihat kisah mereka "dengan kedalaman dan fokus untuk membantu pada hal yang mereka tidak bisa lakukan”. Salah satu cara yang dilakukan dalam model ini adalah mengajukan pertanyaan yang dapat membantu murid mengubah atau merestorasi kehidupannya. ${ }^{31}$

\footnotetext{
${ }^{30}$ Ibid, 248-251.

${ }^{31}$ Ibid, 251.
}

46 - The New Perspective in Theology and Religious Studies, Vol. 1, No. 1, 2020 
Berdasarkan penjelasan di atas, pemuridan naratif sangat relevan untuk diterapkan dalam pelayanan pendidikan Krisiten khusunya di kalangan mahasiswa. Di mana model pemuridan naratif diperuntukkan untuk membangun iman para peserta di lingkungan pendidikan yang siap menjadi dewasa atau mengalami transformasi iman. Perhatian penting bagi pelaku pendidikan dalam menerapkan metode ini adalah, ketika merapkan prinsip ketika, yakni, pembelajaran transformatif, yang diperlukan adalah proses yang kompleks, serta menghadapi dilema dan membutuhkan refleksi yang kritis. Meski demikian proses inilah yang semestinya terjadi dalam kegiatan pendidikan Kristen yakni bertujuan untuk memanusiakan, menuntun peserta (murid) belajar melalui perjalanan dan proses belajar menuju kehidupan yang berkualitas dalam Kristus. Pendekatan pemuridan naratif juga lebih bersahabat, karena tidak dilakukan secara terpaksa atau tergesa-gesa, tetapi dimulai dari tahapan; (1) tahap perkenalan membawa seseorang untuk mengenal identitas diri (2) tahap pendampingan (melibatkan unsur mentoring) untuk menuntun seseorang dari identitas sebagai murid menuju pada kedewasaan, (3) tahapan terakhir adalah transformasi, sebuah proses yang melibatkan upaya eksplorasi secara luas dan lebih mendalam. Dengan pendekatan pemuridan naratif di lingkungan pendidikan, maka pelayanan pendidikan menjadi lebih kaya dan kreatif dan dapat dimodifikasi sesuai dengan konteks dan diterapkan dalam berbagai komunitas yang berhubungan dengan mengembangkan kualitas hidup manusia.

Pendekatan Kepemimpinan yang berpusat pada Murid (disciple)

Pendekatan kepemimpinan yang berpusat pada murid (diartikan pendidikan Kriten yang berpusat pada murid) diperkenalkan oleh Dale L. Lemke. Pertama-tama ia menjelaskan pengertian murid untuk menggambarkan identitas murid dalam pelayanan pemuridan. Karena itu kepemimpinan yang berpusat pada murid adalah pendekatan filosofis untuk pelatihan pelayanan berdasarkan gagasan bahwa murid memiliki aset yang penting dalam hubungan belajar-mengajar. Namun pendekatan ini berbeda dengan kepemimpinan pastoral dan literatur pendidikan Kristen yang dilakukan selama ini, yang selama ini cenderung hanya fokus pada aset, karakter dan peran pemimpin. Mis: (1) John Maxwel, tentang "kepemimpinan klasik dalam hal pengaruh pribadi telah memberikan kerangka penting untuk berpikir tentang peran dan pengaruh para 
pemimpin."32 (2) J. Robert Clinton, ia mendokumentasikan pertumbuhan internal dan proses kematangan pelayanan dengan mengarah pada pengaruh pribadi dan memusatkan pada kepemimpinan. ${ }^{33}$ Lemke tidak setuju dengan kedua pendekatan ini karena ia beranggapan bahwa para pemimpin yang dipanggil untuk memperlengkapi pelayanan harus memberikan perhatian pada karya Roh Kudus dan bukan kepada pemimpin. Bahkan sumber literatur pendidikan dan misi Kristen adalah menetapkan filosofi kepemimpinan yang berpusat pada murid dengan tujuan mengembangkan pemahaman yang lebih luas tentang memperlengkapi para murid untuk melayani di gereja lokal dan di komunitas lain (termasuk komunitas sekolah). ${ }^{34}$ Pendekatan ini sangat diapresiasi oleh C. Estes, bahwa pendekatan ini dapat untuk digunakan sebagai sumber literatur pendidikan, karena memberikan penekanan pada pendidikan yang berpusat pada pelajar (murid). ${ }^{35}$ Bill Hull juga setuju dengan pendekatan Lemke, bahwa sumber utama dari literatur pendidikan adalah kepemimpinan yang berpusat pada murid, sebab murid adalah seorang pembelajar atau pengikut. Sehingga pendekatan pada murid seharusnya paralel dengan literatur pendidikan. ${ }^{36}$

Lemke juga menjelaskan bahwa kepemimpinan yang berpusat pada murid memang dapat dikembangkan dalam sekolah umum, contoh: telah diterapkan di lembaga sekolah Arizona State Univerisity dan Vanderbilt Univerisity, dengan menggunakan istilah kepemimpinan yang berpusat pada "pengikut", paralel dengan terminologi kepemimpinan dalam bidang pendidikan. Kelebihan pendekatan kepemimpinan yang berpusat pada murid adalah pemimpin bukan hanya sekedar meminta para pengikut untuk mengimplementasikan pola pikirnya kepada orang lain, tetapi pemimpin sendiri harus terlebih dahulu mengadopsi dan memodelkan pola pikir yang berpusat pada murid. Model inilah yang diperlihatkan oleh Yesus, Ia prihatin untuk memberdayakan keragaman pengikut-Nya untuk mengejar tujuan Bapa-Nya. Jadi kepemimpinan yang berpusat pada murid adalah proses memengaruhi, mengembangkan, dan memanfaatkan hastrat, keterampilan dan aset lain yang dimiliki

\footnotetext{
${ }^{32}$ Dale L. Lemke, “A Philosophy of Disciple-Centered Leadership”, dalam Christian Education Journal, Series 3, Vol. 14, No. 2, (2017), 270.

${ }^{33}$ Ibid, 270. Lih. J. Robert Clinton, The Making of a Leader: Recognizing the Lesson and Stages of Leadership Development (ed.2), (Colorado Springs, CO: Navpress, 2012).

${ }^{34}$ Ibid, 270.

${ }^{35}$ Ibid, 271. Lih. C. Estes, "The Learning Student-Centered Learning in Experiential Education," dalam Journal Experiential Education, Series 27, Vol. 2, (2004), 141-161.

${ }^{36}$ Ibid, 271. Lih. Bill Hull, The Complete Book of Discipleship: On Being and Making Followers of Christ (Colorado Springs, CO: NavPress, 2006).
}

48 - The New Perspective in Theology and Religious Studies, Vol. 1, No. 1, 2020 
oleh anggota komunitas. ${ }^{37}$ Yang perlu diperhatikan dalam model kepemimpinan yang berpusat pada murid adalah harus mengakui bahwa Tuhan bekerja baik secara organisasional dan organik di dalam komunitas lokal dan dunia. Sehingga tidak meminimalkan sentralitas pada Kristus atau pendekatan pendidikan yang berpusat pada humanistik. ${ }^{38}$ Lemke mengemukakan dua contoh dalam dua bidang yang berbeda, yakni; (1) pendidikan oleh Paulo Freire, (2) misiologi dari Roland Allen yang berpusat pada pelayanan misi gereja.

Pertama dalam bidang pendidikan oleh Paulo Freire. Memang diakui terjadi kontroversi di kalangan Kristen yang berhubungan dengan Freire. Antara lain, ideologi Freire banyak dipengaruhi oleh Karl Marx dibanding dengan Yesus Kristus yang menganggap bahwa kebenaran adalah proses. Tetapi tidak dipungkiri Freire memberi kontribusi terhadap pendidikan bahkan ia merupakan figur pendidikan dalam dunia modern. Pada abad ke 20 Freire dicatat termasuk di antara para pendidik Katolik. Salah satu kontribusi dari Freire adalah mengenai filosofi pendidikan yang berpusat pada peserta didik. Dalam "Pedagogy of Freedom," Freire memberikan dua ide untuk filosofi pendidikan: (1) pendidikan dipahami sebagai formasi etis diri dalam konteks historis yang berbeda dengan menekankan tindakan adil dalam menghadapi penindasan. Dalam pemahaman ini sebagai warga negara yang beretika peserta didik (learners) memiliki kapasitas untuk melakukan perubahan dalam dunia di mana mereka berada. Dengan filosofi ini menantang para pemimpin dan perserta didik agar memiliki tanggung jawab etis untuk bertindak dalam sejarah manusia sebagai agen perubahan. (b) Freire menghubungkan unsur simbolik antara mengajar (teaching) dan belajar (learning), bahwa "Siapa pun yang mengajar akan belajar dalam tindakan mengajar, dan siapapun yang belajar akan mengajar dalam tindakan belajar". Dengan demikian mengajar bukan untuk transfer pengetahuan tetapi menciptakan kemungkinan untuk produksi atau konstruksi pengetahuan. Karena itu menurut Freire belajar adalah perjalanan seumur hidup, dan kunci untuk mempertahankan sikap belajar adalah rasa ingin tahu/kreatif. Dalam menerapkan filosofi pendidikan yang berpusat pada murid membutuhkan pemimpin yang mampu memberikan ruang untuk murid agar dapat merefleksikan dirinya dan mampu menyelidiki secara kritis. Kelemahan dari gagasan Freire adalah ia tidak membangun daya tarik murid untuk mengakui realitas

\footnotetext{
${ }^{37}$ Ibid, 271.

${ }^{38}$ Ibid, 271-272.
}

The New Perspective in Theology and Religious Studies, Vol. 1, No. 1, 2020 - 49 
pengetahuan spiritual dan kebutuhan untuk mencari Tuhan. Padahal kebutuhan ini merupakan asset yang dimuliki oleh murid dan merupakan titik dialog yang sangat penting dalam filosofi kepemimpinan yang berpusat pada murid. ${ }^{39}$

Kedua, pendekatan pada filosofi murid yang diterapkan oleh Roland Allen, seorang misionaris Anglikan di Cina Utara selama 8 tahun pada pergantian abad ke-20. Ia percaya bahwa pusat pelayanan misi gereja terletak pada karya Roh Kudus, yang menumbuhkan pemimpin dan memperluas pengaruh gereja Kristus. Keyakinan tersebut sesuai dengan kepercayaan Pauline (Paulus), bahwa dalam Roh Kudus yang tinggal di antara para petobatnya dan gereja-gereja di mana mereka menjadi anggota. Karya Allen patut dipertimbangkan untuk pelayanan misi secara holistik agar pelayanan misi bukan hanya berdampak pada misi gereja di eranya, berdampak untuk memimpin pelayanan misi gereja sampai pada saat ini. ${ }^{40}$ Tema utama dalam pendekatan Allen adalah Paulus menanam gereja berdasarkan prinsip tanggung jawab bersama, fokus pada unsur-unsur penting pengajaran dan pengembangan kepemimpinan. Sehingga dalam waktu singkat Paulus mampu membangun sebuah gereja dengan dasar yang kuat, dan dapat hidup, serta bertumbuh dalam praktik iman, dapat menyelesaikan masalahnya dan mengatasi semua rintangan baik dari dalam maupun dari luar. Relevansi dari persepektif pendekatan kepemimpinan yang berpusat pada murid adalah pusat pelayanan gereja membutuhkan strategi di mana orang-orang yang datang sebagai murid dan pergi memberitakan Injil, harus belajar sedemikian rupa sehingga mereka dapat menyebarkan Injil. Inilah yang terjadi pada gereja mula-mula ketika mendirikan gereja baru, ketika orang-orang non-Yahudi dibawa ke dalam komunitas, terlebih dahulu murid-murid telah melakukan transformasi budaya dan sosial secara dua arah, yakni ditransformasi (diubahkan) oleh budaya gereja dan juga mengajarkan gereja agar hidup dalam konteks sosial. Dengan demikian murid-murid memiliki aset penting bagi kehidupan komunitas iman. ${ }^{41}$ Model ini memberikan kesempatan kepada peserta untuk terlibat dalam proses yang berkelanjutan untuk memperlengkapi murid lainnya. Pendekatan ini juga paralel dengan panggilan pemuridan dalam Amanat Agung Tuhan Yesus. Di mana terlibih dahulu Yesus memperlengkapi murid-murid-Nya untuk mengetahui pelayanan dalam

\footnotetext{
${ }^{39}$ Ibid, 274-275

${ }^{40}$ Ibid, 276.

${ }^{41}$ Ibid, 276-277.
} 
Kerajaan Allah, kemudian Ia melibatkan mereka dalam pelayanan dan selajutnya Ia mengutus mereka untuk melakukan cara yang sama.

Model kepemimpinan yang berpusat pada murid sangat berpotensi untuk diterapkan dalam pelayanan pendidikan Kristen masa kini. Tetapi karena penerapannya dalam pendidikan Kristen maka harus disesuaikan dengan tujuan dan fungsi dari pendidikan Kristen. Misalnya dari contoh pendekatan ia mengusulkan perspektif filosofis yang merupakan bidang di luar dari praktik pelayanan. Pendekatan ini dapat memberikan ide bagi pendidik untuk belajar dari teori pendidikan, tetapi untuk menerapkan dalam konteks pendidikan Kristen perlu belajar dari sumber lainnya yang dipandang memiliki bidang yang lebih luas dan menawarkan bimbingan bagi para pemimpin atau pendidik Kristen yang terlibat dalam pelayanan untuk membangun dan memperlengkapi orang lain agar dapat mengembangkan diri mereka. Contoh dalam penerapan untuk pendekatan kepemimpinan yang berpusat pada murid, yang dapat dikembangkan dalam konteks pendidikan Kristen masa kini adalah model yang ditunjukkan oleh Allen, di mana ia menekankan karya Roh Kudus sehingga seorang pemimpin dapat membimbing murid-murid untuk menjadi dewasa, serta mampu mengembangkan diri dan mampu menghadapi bahaya dan menyelesaikan masalah secara dewasa. Dan selanjutnya murid-murid dapat melakukan pelayanan yang sama kepada orang lain. Model kepemimpinan yang berpusat pada murid sebaiknya dapat diterapkan sesuai dengan kontek Lemke yakni di kalangan mahasiswa, tetapi tidak menutup kemungkinan dapat diterapkan untuk pemuda awal atau dalam konteks Indonesia di kalangan pelajar Sekolah Menengah Atas. Alasannya dalam tahap usia inilah para pemuda belajar mengambil keputusan penting untuk melanjutkan perjalanan menuju dewasa, sehingga dengan model pendidikan yang berbasis kepemimpinan berpusat pada murid, mereka dipersiapkan untuk mengalami proses belajar dari perjalanan hidup dan mengalami transformasi.

\section{Kesimpulan}

Berdasarkan pembahasan yang telah dipaparkan di atas mengemukakan pelayanan pendidikan Kristen sangat penting dalam membangun dan memperlengkapi para siswa (murid), baik dalam lingkup sekolah formal maupun dalam komunitas Kristen lalinnya, agar orang percaya menjadi murid Kristus yang sejati. Namun dalam 
menerapkan pelaksanaan pendidikan Kristen mengalami kegagalan, baik di sekolah formal yang berbasis sekolah Kristen dan juga dalam komunitas lainnya. Kemudian dalam pemaparan di atas juga dikemukakan bahwa mulai pada pertengahan abad ke-20, metode pendidikan Kristen diterapkan dengan model yang lebih baik dan juga terbukti memberikan dampak terhadap peran pendidikan Kristen. Perubahan yang dilakukan adalah melakukan tugas pendidikan Kristen dengan model pemuridan, dan hal ini dilakukan di Sekolah-sekolah Kristen dan perguruan tinggi. Melalui pendidikan Kristen berbasis pemuridan juga membuka kerja sama yang baik antara gereja dan lembaga sekolah, serta memberikan ruang bagi proses pengajaran pendidikan Kristen yang lebih bersahabat dan melibatkan semua oknum dalam kegiatan belajar, yakni pendidik dan peserta didik sama-sama berperan penting. Kemudian bagian terakhir mengusulkan model pendidikan berbasis pemuridan (relasional, naratif dan kepemimpinan yang berpusat pada murid). Ketiga model yang diusulkan sangat memungkinkan diterapkan dalam pelayanan pendidikan Kristen masa kini, dan terbuka untuk modifikasi dan disesuaikan dengan konteks dan lingkungan pendidikan Kristen berada.

\section{Rujukan}

Barna, George. Menumbuhkan Murid-Murid Sejati. Jakarta: Metanoia, 2010.

Byrd III, Nathan C. "Narrative Discpleship: Guiding Emerging Adults "Connect the Dots" Of Life and Faith", dalam Christian Education Journal, Series 3, Vol. 8, No.2, La Mirada: Biola University, 2011.

Chan, Edmund. A Certain Kind (Yang Tertentu): Pemuridan Intensional yang Mengubah Definisi Sukses dalam Pelayanan. Singapore: Covenant Evangelical Free Church, 2014.

Clinton, J. Robert. The Making of a Leader: Recognizing the Lesson and Stages of Leadership Development (ed.2), Colorado Springs, CO: Navpress, 2012.

Edlin, Richard J. The Cause of the Christian Education, terj. Hakikat Pendidikan Kristen. Jakarta: BPK Gunung Mulia, 2014.

Graham, Donovan L. Teaching Redemptively: Bringing Grace and Truth into Your Classroom. Colorado Sprin, CO: Purposeful Design Publications, 2003/2009. 
Groome, Thomas H. Christian Religious Education: Sharing Our Story and Vision. Terj. Daniel Stefanus, Pendidikan Agama Kristen: Berbagi Cerita dan Visi Kita. Jakarta: BPK Gunung Mulia, 2010.

Himes, Brant. "Dietrich Bonhoeffer As Theological Praxis: A Resource for Educational Ministry" Dalam Christian Education Journal, Series 3. Vol. 8, No. 2, Fuller Theological Seminary, 2011.

Hull, Bill. Jesus Christ, Disciplemaker, terj. Yesus Kristus, Sang Pembuat Murid. Grand Rapids, 2004 / Surabaya: Literatur Perkantas Jawa Timur, 2015.

Klassen, Harold. "Model Ketiga Sekolah Kristen Modern", dalam Transforming Teachers, Okober 2008: https://www.transformingteachers.org. Diakses 10 Desember 2019.

Lemke, Dale L. "A Philosophy of Disciple-Centered Leadership", dalam Christian Education Journal, Series 3, Vol. 14, No. 2, 2017. Copyright: American Theological Library Association, 2016.

Lie, Tan Giok. "Tantangan Pendidikan dan Pengajaran Kristen Masa Kini di Ranah Formal”, dalam STULOS Jurnal Teologi, STT Bandung 2013. Diposting oleh Redaksi e-Reformed: http://reformed.sabda.org. Diakses 10 Desember 2019.

Ogden, Greg. Transforming Discipleship, terj. Pemuridan yang Mengubahkan. Surabaya: Literatur Perkantas Jawa Timur, 2014.

Palmer, Parker J. To Know As We Are Known: Educational As A Spiritual Journey. San Fransisco: Harper \& Row, 1993.

Pazmino, Robert W. Foundation Issues in Christian Education: An Introduction in Evangelical Perspective, terj. Fondasi Pendidikan Kristen: Sebuah Pengantar dalam Perspektif Injil. Grand Rapids, MI: Baker Books, 1997/BPK Gunung Mulia, 2012.

Purba, Asmat. "Pemuridan sebagai Tugas Dosen Pendidikan Agama Kristen di Perguruan Tinggi”, dalam Jurnal Ilmiah Berkala, TEDC Vol, 8 No. 1, Januari 2014

Shirley, Chris. "Overcoming Digital Distance: The Challnge of Developing Relational Disciples in the Internet Age", dalam Christian Education Journal. Seri 3, Vol. 14, No. 2, Dallas Baptist University, 2017.

The New Perspective in Theology and Religious Studies, Vol. 1, No. 1, 2020 - 53 
Tenibemas, Purnawan. "Spiritualitas di Sekolah Tinggi", dalam Jurnal Teologi Pengarah, Bandung: STT Tiranus, Juli 2010.

Westerhoff III, John H. Will Our Children Have Faith? New York: The Seabury Press, 1976.

54 - The New Perspective in Theology and Religious Studies, Vol. 1, No. 1, 2020 